\title{
Biomedical applications of nanotechnology
}

\author{
Ana P. $\operatorname{Ramos}^{1}$ (D) $\cdot \operatorname{Marcos}_{\text {A. E. }}$ Cruz $^{1} \cdot$ Camila B. Tovani $^{1} \cdot$ Pietro Ciancaglini $^{1}$
}

Received: 28 November 2016 / Accepted: 26 December 2016 / Published online: 13 January 2017

(C) International Union for Pure and Applied Biophysics (IUPAB) and Springer-Verlag Berlin Heidelberg 2017

\begin{abstract}
The ability to investigate substances at the molecular level has boosted the search for materials with outstanding properties for use in medicine. The application of these novel materials has generated the new research field of nanobiotechnology, which plays a central role in disease diagnosis, drug design and delivery, and implants. In this review, we provide an overview of the use of metallic and metal oxide nanoparticles, carbon-nanotubes, liposomes, and nanopatterned flat surfaces for specific biomedical applications. The chemical and physical properties of the surface of these materials allow their use in diagnosis, biosensing and bioimaging devices, drug delivery systems, and bone substitute implants. The toxicology of these particles is also discussed in the light of a new field referred to as nanotoxicology that studies the surface effects emerging from nanostructured materials.
\end{abstract}

Keywords Nanobiotechnology · Inorganic particles · Liposomes $\cdot$ Nanopatterned surfaces

\section{Introduction}

Nanotechnology has many definitions and applications. However, all definitions highlight the design and development of highly ordered bottom-up nanostructured materials that offer specific responses when exposed to certain stimuli

Ana P. Ramos

anapr@ffclrp.usp.br

1 Departamento de Química, Faculdade de Filosofia, Ciências e Letras de Ribeirão Preto (FFCLRP), Universidade de São Paulo (USP), 14040-901 Ribeirão Preto, SP, Brazil
(Saji et al. 2010). Surface chemistry and physics "tune" the applications of nanosized materials. The concentration of atoms on the surface of these systems represents up to $90 \%$ of their total mass and results in enhanced reactivity. In this sense, modifying the surface of a nanomaterial in different ways can produce materials with distinct biological properties and functionalities for a specific end application and with improved solubility under physiological conditions (Gupta et al. 2007; Kasemo 2002).

Nanotechnology products have become increasingly useful in biomedicine and have led to the advent of a hybrid science named nanobiotechnology (Saji et al. 2010). Nanomaterials have noteworthy applications in nanobiotechnology, particularly in diagnosis, drug delivery systems (Faraji and Wipf 2009), prostheses, and implants. Nanoscale materials integrate well into biomedical devices because most biological systems are also nanosized. The materials commonly used to develop these nanotechnology products are inorganic and metal nanoparticles, carbon nanotubes, liposomes, and metallic surfaces (Liu et al. 2016a). By using chemical or physical methods and taking advantage of specific biological reactions, such as the antibody-antigen interaction, receptor-ligand interaction, and DNA-DNA hybridization, it is possible to conjugate biospecific molecules with nanoparticles. Surface chemistry (composition) (Castner and Ratner 2002; Moyano and Rotello 2011), surface physics (topography and roughness) (McNamara et al. 2010; Yim et al. 2010), surface thermodynamics (wettability and free energy) (Menzies and Jones 2010), and their toxicological effects determine the specific application of nanomaterials.

In this review we discuss the biomedical applications of nanoparticles and nanopatterned surfaces (Fig. 1), including surface features and modifications which are responsible for tuning their response when in contact with biological environments. The design of nanostructures by controlling their 


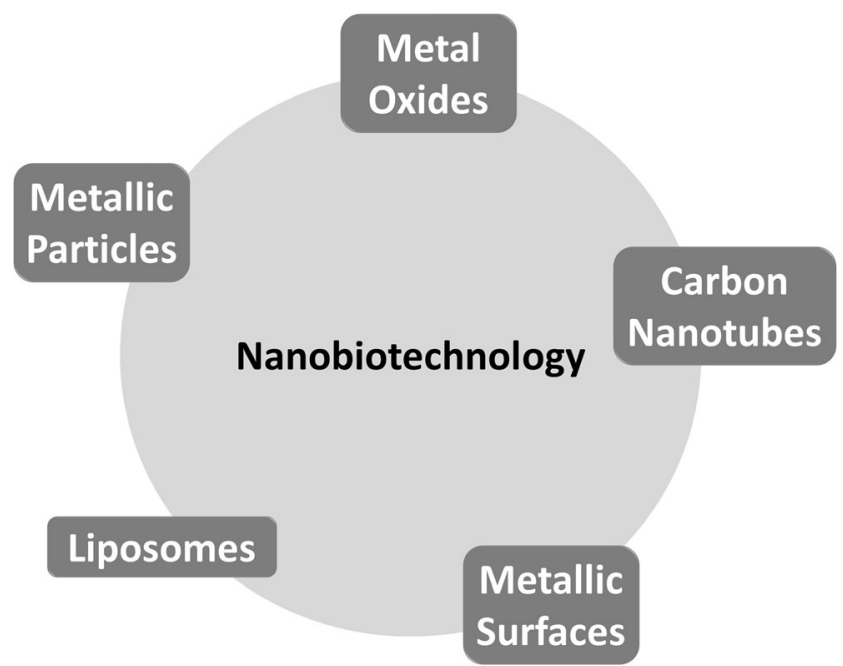

Fig. 1 Nanobiotechnology and its main tools

surface properties is presented as a strategy to achieve improved responses aimed at a specific application. In this context we focus on the use of inorganic (metallic and metal oxide) and organic (carbon-nanotubes and liposomes) nanoparticles and nanopatterned flat surfaces in diagnosis, biosensing and bioimaging devices, drug delivery systems, and bonesubstituting implants. The toxicology of these particles is also discussed in the light of a new field referred to as nanotoxicology that studies the surface effects emerging from nanostructured materials.

\section{Biomedical applications of metal oxide nanoparticles}

Metal oxide nanoparticles have been employed to construct several medical devices. The magnetic properties of iron oxide have been used for therapeutic and diagnostic purposes, such as contrast agents for magnetic resonance imaging, magnetic particle imaging, and ultrasonic techniques (e.g. magneto-motive ultrasound (Oh et al. 2006), photoacoustic imaging, and magnetic particle hyperthermia (Gupta and Gupta 2005; Liu et al. 2016b). The electronic structure of zinc oxide $(\mathrm{ZnO})$ is useful for biomedical applications; for example, the intrinsic fluorescence of $\mathrm{ZnO}$ nanowires has been employed to image cancer cells (Hong et al. 2011). To this end, functionalization of the surface of $\mathrm{ZnO}$ nanowires increases their solubility in water and their biocompatibility and reduces their cellular toxicity.
Functionalization of the $\mathrm{ZnO}$ surface with specific biomolecules creates photosensitive biosensors (Liu et al. 2006).

The high surface area of nanoparticles favors the prompt adsorption of plasma proteins (Deng et al. 2009). Hence, the chemical composition and physical topography of the surface of nanoparticles and the combination of these properties (wettability, surface-free energy) tailor the interaction of the particles with different compounds and dictate their end application (Fig. 2).

Titanium oxide $\left(\mathrm{TiO}_{2}\right)$ has a wide range of biomedical applications (Fei Yin et al. 2013). For instance, in bone-substituting materials, the biofluid first makes contact with a thin $\mathrm{TiO}_{2}$ layer that spontaneously emerges on the top surface of metallic titanium (Hanawa 2011; Feng et al. 2003). This has motivated the use of $\mathrm{TiO}_{2}$ nanoparticles for bone regeneration (He et al. 2008; Kubota et al. 2004; Brammer et al. 2012; Tan et al. 2012). Zirconium oxide has recently been used for dental implants because, like titanium, it is compatible with the same type of hard tissues (Koch et al. 2010; Özkurt and Kazazoğlu 2011).

\section{Metal nanoparticles}

The strong optical absorption related to the surface plasmon resonance of noble metals makes them suitable for constructing molecular contrast devices (Liao et al. 2006; Bhattacharya and Mukherjee 2008). Absorption and scattering in the visible and near-infrared regions have stimulated the application of materials containing metal nanoparticles in the fields of sensing and diagnosis. Gold nanoparticles can be deposited on appropriate substrates or added to substrate formulation to enhance luminescence (Bhattacharya and Mukherjee 2008). The application of this technology depends on the size and geometry of the particles because these determine their absorption/scattering properties. Gold nanorods absorb in the near-infrared and have been used to monitor the blood flow in vivo using photoacoustic imaging (Wang et al. 2005). The literature contains examples of applications that used gold nanocages, nanoshells, and nanospheres (Liao et al. 2006). It is possible to modify the surface of gold nanoparticles with sulfur-containing compounds because gold and sulfur have a high chemical affinity (Schmidt and Healy 2009; Moyano and Rotello 2011). Modification of gold nanoparticles with biospecific compounds enhances binding to specific tissues (Faraji and Wipf 2009). For example, surface-labeled gold

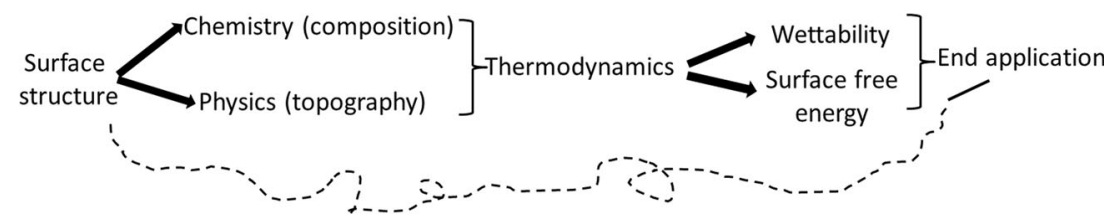

Fig. 2 Correlation between the main chemical and physical properties of the surface of nanoparticles and the end nanobiotechnological application of nanomaterials 
nanoshells have been used to target cancer cells in vitro (Bhattacharya and Mukherjee 2008) and the results confirmed by optical microscopy.

Given all the advantages of using noble metal nanoparticles for biomedical applications, silver nanoparticles (AgNPs) have also attracted interest. Some biosensing applications are based on spectral modifications due to aggregated particles (Liao et al. 2006; Moyano and Rotello 2011). These particles display well-known antibacterial activity as well as an antiinflammatory action (Chaloupka et al. 2010). The preparation of AgNPs is straightforward (Guidelli et al. 2011, 2012) as their size is easy to control, and they can be incorporated into different materials without difficulty (Guidelli et al. 2013; Guidelli et al. 2016). Published reports describe the use of silver as a coating in materials for cardiovascular implants and central venous and neurosurgical catheters (Chaloupka et al. 2010; Chen and Schluesener 2008).

Polymers used as bone cement (Alt et al. 2004) and wound dressing (Tian et al. 2007) have also been loaded with AgNPs and their antimicrobial responses compared to standard antibiotics and silver salts compared. Only AgNPs-bone cement combines high antibacterial activity with low cytotoxicity as compared to silver salt and gentamicin-bone cement (Alt et al. 2004). Controlled delivery coupled to small particle size is one strategy to reduce toxicity. AgNPs have been added to latex membranes used for skin regeneration (Guidelli et al. 2013), with the membranes acting as a biomaterial and controlling the nanoparticle delivery rate (Abukabda et al. 2016).

\section{Carbon nanotubes}

The physical and chemical properties of carbon nanotubes (CNTs) have motivated their application in several areas of science. Modification of the surface of these particles and their functionalization with biological molecules at the molecular level has increased their use in nanobiotechnology (Yang et al. 2007; Prato et al. 2008; Sharma et al. 2016). These modified particles provide well-dispersed samples that are compatible with physiological conditions (Williams et al. 2002). In this context, nanotubes might be useful drug delivery vehicles because their nanometer size enables them to move easily inside the body (Pastorin et al. 2006; Faraji and Wipf 2009). The bioavailability of methotrexate, a drug used in cancer therapy, increases when it is administered after being immobilized on a double-functionalized carbon nanotube surface (Pastorin et al. 2006). The active compound can be inserted inside the tube or it can bind to the surface of the particle with the aim to target and alter cell behavior at the subcellular or molecular level. Moreover, biofunctionalized single- or multi-walled CNTs can be taken up by a wide range of cells, traffic through different cellular barriers (Yang et al. 2007), and interact with DNA (Pantarotto et al. 2004a).
Cationic CNTs complexed with plasmid DNA. can also be taken up by cells and interact with DNA (Pantarotto et al. 2004b). CNTs are suitable scaffolds for the proliferation of osteoblasts (Zanello et al. 2006; Zancanela et al. 2016) and for the regeneration of bones (Zhao et al. 2010; Yoon et al. 2014). We have demonstrated that the toxicity of unmodified single- and multi-walled CNTs is concentration-dependent and that at concentrations of up to $10^{-2} \mathrm{mg} / \mathrm{mL}$, they particles can be safely used in osteoblast cultures (Zancanela et al. 2016). We recently proposed the use of collagen-modified calcium carbonate nanotubes as a new generation of tubular structures for bone regeneration (Tovani et al. 2016).

\section{Liposomes and nanobiotechnology}

Liposomes are small artificial lipid-bilayer spherical vesicles that were first reported by Bangham and Horne (1964). Liposomes with different properties can be achieved by tuning their composition, surface charge, and size. The rigidity and fluidity of the bilayer can also be tailored by choosing specific lipids (Akbarzadeh et al. 2013). These artificial membrane models can be classified on the basis of their diameter. Small unilamellar vesicles range in size from 20 to $100 \mathrm{~nm}$, whereas large unilamellar vesicles (LUVs) range from 200 to $1000 \mathrm{~nm}$. The vesicles consist of a single lipid bilayer and an internal aqueous cavity. Liposomes can also be classified according to the number of lipid bilayers. Multilamellar vesicles are formed by multiple, concentric phospholipid bilayers intercalated with aqueous compartments, with diameters ranging from 400 to $3500 \mathrm{~nm}$ (Akbarzadeh et al. 2013; Bilia et al. 2014).

Over the last two decades, liposomes have been widely employed as drug delivery systems for cancer and gene therapy and vaccines, among other uses (Madni et al. 2014; Liu and Chen 2015). These vesicles can deliver a range of bioactive compounds, such as antioxidants, antimicrobials, and angenic proteins (Simão et al. 2015). The functionality of these molecules is preserved after encapsulation (Benech et al. 2002; Shehata et al. 2008; Akbarzadeh et al. 2013; Gao et al. 2014). Moreover, compounds with different solubility can be encapsulated inside the aqueous cavity or at the surface of the lipid bilayers (Ghalandarlaki et al. 2014; Reimhult 2015). Because liposomes are potentially atoxic, degradable under physiological conditions, and non-immunogenic, they can be expected to deliver drugs with a low degradation rate, with diminished collateral effects (Ravi-Kumar 2000; Ghalandarlaki et al. 2014).

More than materials for drug delivery, liposomes can also be used as biomimetic models to study how membranes interact with hydrophobic drugs and proteins. Actually, proteinassociated liposomes (proteoliposomes) can be employed to investigate the action of photosensitive dyes applied during photodynamic therapy (Bolfarini et al. 2012; Longo et al. 
2012; Faria et al. 2015) to prevent/treat several diseases (Daghastanli et al. 2004; De Lima Santos et al. 2005; Zucolotto et al. 2007; Ciancaglini et al. 2012; Simão et al. 2015). Proteoliposomes can be used to study how the protein-lipid interactions specifically affect the surface of the membrane model. The scientific community has highlighted this approach as an excellent tool to understand biochemical and biophysical phenomena and to evaluate biotechnological applications (Camolezi et al. 2002; Ierardi et al. 2002; Daghastanli et al. 2004; De Lima Santos et al. 2005; Rigos et al. 2008; Santos et al. 2009; Bolean et al. 2010, 2011, 2015; Simão et al. 2010a, 2010b; Barbosa et al. 2011; Yoneda et al. 2013, 2014; Simão et al. 2015; Dong et al. 2016; Elkhodiry et al. 2016).

\section{Nanotechnology to engineer the surface of metallic implants}

Nanotechnology has also found applications in tissue and implant engineering. The possibility to enhance the surface area of the material and to tune the roughness of its surface at the nanometric scale should yield better biological responses of osteogenic cells and effective mechanical contact between tissue and implant. Titanium and its alloys are considered to be the most attractive materials for bone replacement applications (Rack and Qazi 2006). The widespread use of this metal is due to its improved mechanical properties, high resistance to corrosion, low surface reactivity, and acceptable biocompatibility in vivo and in vitro. The live tissue heals in close apposition to the metal, although there may be a thin fibrous layer separating the metallic implant and the bone that represents a failure in the osteointegration process. In this context, it is necessary to modify the surface of the implant to create a stronger boneimplant interface and to achieve successful osteointegration (Puleo and Nanci 1999; Le Guéhennec et al. 2007). At first glance, modification of the surface should only change the topography (Le Guéhennec et al. 2007). However, the addition of bioactive compounds and the creation of roughness at the nanometer level appear to be more promising strategies for biomedical applications. In the following subsections, we review which factors must be modified on the surface of implants if better host tissue responses are to be achieved. We also describe how nanotechnology is being used to engineer the surface of implants at the nanometer scale.

\section{Why modify an implant surface?}

The aim of modifying metallic surfaces is to improve the contact between the implant and the live tissue in bonesubstitution applications (Jalota et al. 2007). Successful orthopedic implant osteointegration relies on the quick and efficient formation of bone tissue at the surface of an implant
(Albrektsson et al. 1981). A cell never encounters a completely clean surface; instead, it comes into contact with a surface conditioned by water molecules, ions, and adsorbed proteins. Therefore, water interactions, protein adsorption, and cell attachment are the first events taking place at the tissue-implant interface after implantation (Puleo and Nanci 1999). This conditioned surface dictates cell attachment and the resulting morphology and behavior of the cell. All these early events at the bone-implant interface are determined by properties of the surface, such as topography, wettability, charge, and chemical composition (Chen et al. 2014). Surface engineering ensures that an implant with an optimized surface is achieved by manipulating these properties to maximize anchorage of the implant to the tissue. The need to modify the surface is clear from clinical observations indicating that bone growth rate is higher moving away from the implant surface than toward the implant surface (Puleo and Nanci 1999).

In the case of bone-substitution materials, roughness governs the amount of bone tissue that is in close contact with the surface of the implant (Wennerberg et al. 1998). In this context, topographic features, such as valleys, peaks, and grooves, act as points for cell anchorage and protein adsorption (Lampin et al. 1997; Anselme et al. 2000; Webster et al. 2000; Jayaraman et al. 2004). For materials with the same surface chemistry, cell growth will be driven by topographic features (Rosales-Leal et al. 2010). Rougher surfaces promote higher adhesion of osteoblasts (Martin et al. 1995; Webster and Ejiofor 2004) and dictate the metabolism of these cells regulating gene expression (Brett et al. 2004), the synthesis of collagen (Boyan et al. 2001; Wennerberg and Albrektsson 2009), and the activation of integrins (Khang et al. 2012). Manipulation of the topography of a surface at the nanoscale level has been shown to positively affect cell behavior (Khang et al. 2012). Osteogenesis starts faster on surfaces organized at the nanometer level than on smooth surfaces (Riehle et al. 2003; Webster and Ejiofor 2004; Sato et al. 2005). Therefore, manipulation of the nanotopography of a biomaterial can stimulate and control cellular behavior such as attachment, migration, spreading, gene expression, proliferation, differentiation, and secretion of matrix components (Klymov et al. 2013). Creating materials organized at the nanometric level can be an effective strategy to target the cell recognition process (Brunetti et al. 2010) and may affect the interaction of solvent molecules with the surface, thus impacting the interfacial energy of the material (Kuna et al. 2009).

Wettability determines how cells and fluids interact with surfaces. Wettability refers to the ability of a fluid to spread on a given surface. It is related to the equilibrium of forces acting at the solid-liquid interface and is governed by the topography of the surface (Quéré 2008). In biomaterials science, wettability is assessed by measuring contact angles $(\theta)$ between a liquid drop and the surface (Menzies and Jones 2010). When this liquid is water, surfaces where the water droplets 
spontaneously spread over the surface $\left(\theta<90^{\circ}\right)$ are considered to be hydrophilic; if $\theta$ is $>90^{\circ}$, the surface is considered to be hydrophobic. However, this classical limit between a hydrophilic and a hydrophobic surface has been reviewed due to the specific structure of water molecules at the interface (Berg et al. 1994; Vogler 1998). The value of $\theta$ is measured at the solid-liquid-gas interface and is univocally fixed by the chemical nature of the different phases and the equilibrium forces acting among these phases. Contact angles are mathematically correlated by the Young-Dupré equation (Kwok and Neumann 1999), namely, $\cos (\theta)=\left(\gamma_{\mathrm{SG}}-\gamma_{\mathrm{SL}}\right) \gamma_{\mathrm{LG}}$, where $\gamma$ is the interfacial tension between the solid (S), liquid $(\mathrm{L})$, and gas $(\mathrm{G})$ phases. In particular, $\gamma_{\mathrm{SG}}$ is called the surface free energy (SFE) of a solid. SFE is an important parameter because it can be determined by using chemical models that depend not only on $\gamma_{\mathrm{SL}}$ and $\gamma_{\mathrm{LG}}$, but also on specific intermolecular forces. Hence, the total SFE can be seen to be the result of the combination of dispersive forces $\left(\gamma_{\mathrm{SG}}^{\mathrm{d}}\right)$ and polar forces $\left(\gamma_{\mathrm{SG}}^{\mathrm{p}}\right)(\mathrm{Kwok}$ and Neumann 1999). Thus, the SFE of a biomaterial selectively determines how either the polar or the non-polar portion of proteins and cell membranes interact with the surfaces.

To achieve a specific effect for biomedical applications, the type of protein and the manner in which the protein is adsorbed onto the implant are more important than the amount of adsorbed protein. Replacement of the initially adsorbed proteins with other proteins that display a higher affinity dictates the bioactivity of the surface of a biomaterial (Tirrell et al. 2002). The protein layer absorbed onto the surface of the implant will determine how cells attach and spread, thereby influencing cell maturation. Arima and Iwata (2007) showed that albumin can block cell-implant interaction by strongly binding to hydrophobic surfaces, thus inhibiting replacement by other extra-cellular matrix (ECM) proteins. On the other hand, when adsorbed albumin binds to hydrophilic groups, it can indeed be replaced with ECM proteins. Consequently, the type of protein and the type of binding govern cellular adhesion and migration processes (Arima and Iwata 2007). Cells can non-specifically adhere to surfaces through ionic and van der Waal's forces, or they can specifically adhere to the surface via adsorbed protein clusters (Anselme 2000). In osteoblasts, integrin receptors recognize motifs such as Arg-Gly-Asp (RGD) on proteins like fibronectin and vitronectin to form local focal adhesions. The formation of these adhesions activates a cascade of intracellular signaling pathways that affect cell behavior (Hendesi et al. 2015). Recognition of this integrin-mediated cell attachment mechanism has inspired scientists to modify metallic surfaces by immobilizing sequences of RGD-peptides (Ferris et al. 1999; Rammelt et al. 2006). Thus, surface modification adds another dimension to bioactive coating by altering not only the chemistry but also the topography; in this context, manipulating the SFE of the surface might be the more promising strategy to stimulate the cell adhesion process.
Kilpadi et al. (2001) observed that hydroxyapatite (HAp) adsorbs more ECM proteins and binds more integrins and osteoblast precursor cells than pure titanium or steel. Therefore, the addition of bioactive compounds (e.g., bioactive polar groups) to the metallic surface could be an alternative approach to tailoring SFE and cell behavior. On hydrophobic surfaces, human fetal osteoblasts express significantly lower levels of the $\alpha 5$ and $\beta 3$ integrin subunits than cells cultured on hydrophilic surfaces (Lim et al. 2005). Moreover, surfaces containing polar groups $\left(\mathrm{COOH}\right.$ and $\left.\mathrm{NH}_{2}\right)$ display an enhanced activity of integrins, which leads to a higher adhesion and spreading of fibroblast cells (Faucheux et al. 2004). Using macrocrophage cultures, Hotchkiss et al. (2016) observed that materials with high surface wettability produced an antiinflammatory microenvironment through activation of macrophages and the production of cytokines, indicating it is crucial to control wettability when attempting to improve the healing response to biomaterials.

\section{Bio-inspired modifications of surfaces}

The addition of bioactive minerals inspired by the bone structure has been one of the most commonly used strategies to modify metallic surfaces of the implant. Biomimetics is a desirable strategy because it predefines nanochemical and/or nanophysical structures. The manufacture of coatings based on calcium phosphates $(\mathrm{CaP})$ is common in biomaterials science, and the application of such coatings to the implant significantly affects the bone regeneration process (Surmenev et al. 2014). HAp is a calcium orthophosphate mineral that resembles the biological apatite found in bone tissue, where HAp crystals are hierarchically organized into the array of collagen fibers (Olszta et al. 2007). At the commercial level, plasma spray (Surmenev 2011) and sputtered coating (Yang et al. 2005) techniques produce apatite coatings. However, such methods are complex and require extremely high temperatures as well as expensive equipment. Moreover, these mechanically based methods pose some challenges: homogeneous thickness and crystallinity are difficult to achieve, coating adhesion is low, $\mathrm{CaP}$ phases change during the coating process, and particles are released from the surface (Le Guéhennec et al. 2007; Surmenev 2011).

Inspired by the $\mathrm{CaP}$ growth process in in vivo systems, physiological solutions or media have also been used to produce $\mathrm{CaP}$ coatings. This methodology allows the formation of continuous $\mathrm{CaP}$ coatings with controlled surface topography (Costa et al. 2012), but it can require long exposure times (Tas 2014). Simulated body fluid (SBF) is one of the most frequently used physiological solution (Kokubo et al. 1990; Cüneyt Tas 2000). SBF consists of a supersaturated CaP solution that simulates the $\mathrm{pH}$ and ionic composition of human body fluid and is a standard method employed to evaluate the bioactivity of materials (Kokubo and Takadama 2006). The use of 
biomimetic saturated solutions to grow $\mathrm{CaP}$ coatings is advantageous because these solutions promote immobilization of biofunctional substances, such as therapeutic agents, bone morphogenic proteins, and growth factors within the CaP layer, to create hybrid coatings that tailor specific cell responses.

One approach to surface modification science is to grow biominerals using organic templates to guide crystal growth. Several organic matrices, such as self-assembled monolayers (Tanahashi and Matsuda 1997; Han and Aizenberg 2003), polymers (Wei and Ma 2004; Xu et al. 2014; Nogueira et al. 2016), and collagen-based structures (Ehrlich 2010; Pastorino et al. 2014; Jin et al. 2015), have been used to study the growth of biominerals. However, there has been little exploration of the use of organic matrices to mediate the formation of hybrid coatings on metallic surfaces (Walsh et al. 2001; Xia et al. 2012). Two promising techniques involve templating biomineral coatings using Langmuir-Blodgett (LB) and layer-by-layer (LbL) films (de Souza et al. 2014a; Cruz and Ramos 2016). LB films are structured molecular films of amphiphilic molecules and are a well-known biomembrane model used to understand and to mimic biological events (Caseli et al. 2015). When a solution of an insoluble amphiphilic molecule is spread on an aqueous subphase, the molecules tend to adsorb spontaneously at the air-liquid interface, to form Langmuir monolayers. If a support is passed through the monolayer, LB films can be built up by deposition of the condensed Langmuir monolayer on the surface of the support. Manipulation of the immersion and withdrawal of the support through the monolayer creates LB films containing as many layers as desired. By judiciously choosing the amphiphilic molecules, $\mathrm{Ca}^{2+}$ can interact with the molecule polar heads, which affords a well-ordered $\mathrm{Ca}^{2+}$ array for biomineral growth after the biomineral is deposited on metallic surfaces (Costa and Maquis 1998; Zhang et al. 2004; de Souza et al. 2014b; Cruz et al. 2016). We have reviewed the growth of homogeneous, nanostructured, and continuous carbonated-HAp coatings on titanium and stainless steel surfaces using dihexadecyl phosphate (DHP) LB films as template. We achieved hybrid coatings with high roughness and wettability, which increased the proliferation of osteoblasts (de Souza et al. 2014b). Moreover, the LB technique allows the immobilization of different molecules (drugs, proteins) in the organic matrix as an alternative to building hybridbiofunctional coatings. LB films have also been used as a template to grow other mineral-based coatings, mainly $\mathrm{CaCO}_{3}$ thin films (Cruz et al. 2016). $\mathrm{CaCO}_{3}$ has been widely employed in bone surgery (Lopez et al. 1992; Piattelli et al. 1997; Yukna and Yukna 1998; Fujihara et al. 2005) and is a biocompatible osteoconductive material (Piattelli et al. 1997; Fricain et al. 1998). Our group reported the growth of particulate $\mathrm{CaCO}_{3}$ thin films on titanium surfaces using DHP-LB films as template (Cruz et al. 2016). This hybrid coating was highly bioactive as assessed by the increased proliferation of osteoblasts and the shorter growth times (only $36 \mathrm{~h}$ ) that were necessary to grow HAp after exposure to SBF.

The $\mathrm{LbL}$ technique is based on alternating and consecutive adsorption of opposite molecules onto solid surfaces as proposed by Decher et al. (1992). It has been used to create different hierarchical organic matrixes (Lvov et al. 1995; Decher et al. 1998; Xiao et al. 2016). In the case of polymeric-based LbL films, the choice of polyanions allows $\mathrm{Ca}^{2+}$ to interact with the negatively charged groups present in the polymer chain, resulting in the organization of an ionic array for biomineral growth. The $\mathrm{LbL}$ technique is a versatile approach that can be used to manipulate the properties of the hybrid coatings. Ramos et al. $(2008 ; 2012)$ controlled the morphology and the formation of $\mathrm{CaCO}_{3}$ polymorph by changing the polyelectrolytes used in the $\mathrm{LbL}$ matrixes deposited onto metallic surfaces. Cruz and Ramos (2016) reported that the LbL-hybrid coatings containing $\mathrm{CaCO}_{3}$ particles rapidly develop into HAp after exposure to SBF, which attests to the high bioactive properties of the resulting coatings.

\section{Toxicology of nanomaterials}

Despite the promising biomedical applications of nanomaterials, knowledge of their toxicological effects is lacking (Krug and Wick 2011). The toxicity of nanomaterials depends on a wide range of parameters, including dose and composition, as well as physicochemical properties, such as size, surface charge, roughness, crystalline structure, and shape (Oberdörster 2010).

The physicochemical properties of materials depend on their dimensions. Consequently, the toxicological behavior of the bulk material induces nanospecific toxic events (Verma and Stellacci 2010). The term nanotoxicology has been used to improve our understanding of the physicochemical properties of nanoparticles and their toxic effects (Kim et al. 2005; Jiang et al. 2008). Most nanotoxicological research is based on studies involving cell culture (Carlson et al. 2008). Several investigations have employed simple biomimetic cell membrane models, such as Langmuir monolayers (Hartono et al. 2009), and proteins in vitro (Karmali and Simberg 2011). However, as data obtained from in vitro experiments may not reflect their in vivo effects (Fadeel and Garcia-Bennett 2010), verification in vivo experiments is needed (Kim et al. 2005; Mahmoudi et al. 2012) to predict how nanomaterials interact with biological systems.

Although many assays have been carried out, inconsistency in methodologies has led to wrong toxicological interpretations. For example, classic toxicology examines exposure time and dose, but the toxicological effects of nanomaterials do not fit with this concept (Elsaesser and Howard 2012). The use of suitable dose metrics needs to be carefully considered. 
To compare the effect of nanoparticle size on its toxicity, numerous studies have pointed out that the total surface area should be considered as the dose (Jiang et al. 2008; Dhawan et al. 2009) because the main phenomena occur at the surface of the nanomaterials and not in the bulk as in the case of regular toxicological assays (Verma and Stellacci 2010). In this sense, comprehensive characterization of the material is critical to associate the toxicity with the correct parameters and properties of nanomaterials and to allow comparison among literature data.

Another concept that needs to be incorporated into toxicological studies is the transformation of the surface of nanomaterials upon contact with the physiological environment. These changes are key to understanding their biological behavior (Nowack and Bucheli 2007). In biological media, before making contact with cells, the nanomaterial interacts with the body fluid, an aqueous media of proteins and biomolecules. In physiological media, the nanomaterial is covered with proteins, resulting in a "corona" (Cedervall et al. 2007; Lundqvist et al. 2011) and a dramatic change in both the properties of the surface of the nanoparticles and their biological identity. The composition of the corona depends on the size and the surface characteristics of the nanoparticle, which will determine protein binding specificities and affinities. Studies have shown that this corona is the first layer to be recognized by cells (Lundqvist et al. 2011). Therefore, the physicochemical properties of the nanomaterial + corona system should be taken into account when predicting its biological fate (Lynch and Dawson 2008).

Establishing the real effect of nanomaterials in biological systems is a challenging task (Dhawan et al. 2009). Nonetheless, in order to take advantage of the potential application of nanomaterials to medicine, a detailed understanding of their potential toxicity is necessary (Kunzmann et al. 2011). However, the relationship between toxicity and physicochemical properties should always be interpreted cautiously to minimize false results (Kroll et al. 2009).

Acknowledgements The authors thank the São Paulo Research Foundation (FAPESP - grant 2013/12615-0, 2014/11941-3, 2014/24249-0, 2012/20946-3 and 2015/08774-0) and the National Council of Technological and Scientific Development (CNPq- grant 44283412014-4) for financial support. Camila B. Tovani and Marcos A. E. Cruz thank FAPESP for the PhD and MSc scholarships, respectively. Ana P. Ramos and Pietro Ciancaglini are CNPq researchers.

\section{Compliance with ethical standards}

Conflict of interests Ana P. Ramos declares that she has no conflicts of interest. Marcos A.E. Cruz declares that he has no conflicts of interest. Camila B. Tovani declares that she has no conflicts of interest. Pietro Ciancaglini declares that he has no conflicts of interest.

Ethical approval This article does not contain any studies with human participants or animals performed by any of the authors.

\section{References}

Abukabda AB, Stapleton PA, Nurkiewicz TR (2016) Metal nanomaterial toxicity variations within the vascular system. Curr Environ Health Rep 3:379-391. doi:10.1007/s40572-016-0112-1

Akbarzadeh A, Rezaei-sadabady R, Davaran S et al (2013) Liposome : classification, preparation, and applications. Nanoscale Res Lett 8:1. doi:10.1186/1556-276X-8-102

Albrektsson T, Brånemark P, Hansson H, Lindström J (1981) Osseointegrated titanium implants: requirements for ensuring a long-lasting, direct bone-to-implant anchorage in man. Acta Orthop 52:155-170. doi:10.3109/17453678108991776

Alt V, Bechert T, Steinrücke P et al (2004) An in vitro assessment of the antibacterial properties and cytotoxicity of nanoparticulate silver bone cement. Biomaterials 25:4383-4391. doi:10.1016/j. biomaterials.2003.10.078

Anselme K (2000) Osteoblast adhesion on biomaterials. Biomaterials 21: 667-681. doi:10.1016/S0142-9612(99)00242-2

Anselme K, Bigerelle M, Noel B et al (2000) Qualitative and quantitative study of human osteoblast adhesion on materials with various surface roughnesses. J Biomed Mater Res 49:155-166. doi:10.1002/(SICI)1097-4636(200002)49:2<155::AID-JBM2 $>3.0 . \mathrm{CO} ; 2-\mathrm{J}$

Arima Y, Iwata H (2007) Effect of wettability and surface functional groups on protein adsorption and cell adhesion using well-defined mixed self-assembled monolayers. Biomaterials 28:3074-82. doi:10.1016/j.biomaterials.2007.03.013

Bangham AD, Horne RW (1964) Negative staining of phospholipids and their structural modification by surface-active agents as observed in the electron microscope. J Mol Biol 8:660-668. doi:10.1016/S00222836(64)80115-7

Barbosa SC, Cilli EM, Dias LG et al (2011) Labaditin, a cyclic peptide with rich biotechnological potential: preliminary toxicological studies and structural changes in water and lipid membrane environment. Amino Acids 40:135-144. doi:10.1007/s00726-010-0648-6

Benech RO, Kheadr EE, Lacroix C et al (2002) Antibacterial activities of nisin $\mathrm{Z}$ encapsulated in liposomes or produced in situ by mixed culture during cheddar cheese ripening antibacterial activities of nisin $\mathrm{Z}$ encapsulated in liposomes or produced in situ by mixed culture during cheddar cheese ripe. Appl Environ Microbiol 68: 5607-5619. doi:10.1128/AEM.68.8.3683

Berg JM, Eriksson LGT, Claesson PM, Borve KGN (1994) Threecomponent langmuir-blodgett films with a controllable degree of polarity. Langmuir 10:1225-1234. doi:10.1021/la00016a041

Bhattacharya R, Mukherjee P (2008) Biological properties of "naked" metal nanoparticles. Adv Drug Deliv Rev 60:1289-1306. doi:10.1016/j.addr.2008.03.013

Bilia AR, Guccione C, Isacchi B et al (2014) Essential oils loaded in nanosystems: a developing strategy for a successful therapeutic approach. Evid Based Complement Alternat Med. doi: $10.1155 / 2014 / 651593$

Bolean M, Simão AMS, Favarin BZ et al (2010) The effect of cholesterol on the reconstitution of alkaline phosphatase into liposomes. Biophys Chem 152:74-79. doi:10.1016/j.bpc.2010.08.002

Bolean M, Simão A, Favarin B (2011) Thermodynamic properties and characterization of proteoliposomes rich in microdomains carrying alkaline phosphatase. Biophys Chem 158:111-118. doi:10.1016/j. bpc.2011.05.019

Bolean M, Simão AMS, Kiffer-Moreira T et al (2015) Proteoliposomes with the ability to transport $\mathrm{Ca}^{2+}$ into the vesicles and hydrolyze phosphosubstrates on their surface. Arch Biochem Biophys 584: 79-89. doi:10.1016/j.abb.2015.08.018

Bolfarini GC, Siqueira-Moura MP, Demets GJF et al (2012) In vitro evaluation of combined hyperthermia and photodynamic effects using magnetoliposomes loaded with cucurbituril zinc 
phthalocyanine complex on melanoma. J Photochem Photobiol B 115:1-4. doi:10.1016/j.jphotobiol.2012.05.009

Boyan BD, Dean DD, Lohmann CH, et al. (2001) The titanium-bone cell interface in vitro: the role of the surface in promoting osteointegration. In: Brunette DM, Tengvall P, Textor M, Thomsen P (eds) Titanium in medicine. Springer, Berlin, Heidelberg, pp 561-585

Brammer KS, Frandsen CJ, Jin S (2012) $\mathrm{TiO}_{2}$ nanotubes for bone regeneration. Trends Biotechnol 30:315-322. doi:10.1016/j.tibtech.2012.02.005

Brett PM, Harle J, Salih V et al (2004) Roughness response genes in osteoblasts. Bone 35:124-33. doi:10.1016/j.bone.2004.03.009

Brunetti V, Maiorano G, Rizzello L et al (2010) Neurons sense nanoscale roughness with nanometer sensitivity. Proc Natl Acad Sci USA 107: 6264-6269. doi:10.1073/pnas.0914456107

Camolezi FL, Daghastanli KRP, Magalhães PP et al (2002) Construction of an alkaline phosphatase-liposome system: a tool for biomineralization study. Int J Biochem Cell Biol 34:1091-1101. doi:10.1016/S1357-2725 (02)00029-8

Carlson C, Hussain SM, Schrand AM et al (2008) Unique cellular interaction of silver nanoparticles : size-dependent generation of reactive oxygen species unique cellular interaction of silver nanoparticles : size-dependent generation of reactive. J Phys Chem B 112:13608 13619. doi:10.1021/jp712087m

Caseli L, Nobre TM, Ramos AP et al (2015) The role of langmuir monolayers to understand biological events. ACS Symp Ser 1215:65-88. doi:10.1021/bk-2015-1215.ch004

Castner DG, Ratner BD (2002) Biomedical surface science: foundations to frontiers. Surface Sci 500(1-3):28-60

Cedervall T, Lynch I, Lindman S et al (2007) Understanding the nanoparticle-protein corona using methods to quantify exchange rates and affinities of proteins for nanoparticles. Proc Natl Acad Sci USA 104:2050-2055. doi:10.1073/pnas.0608582104

Chaloupka K, Malam Y, Seifalian AM (2010) Nanosilver as a new generation of nanoproduct in biomedical applications. Trends Biotechnol 28:580-588. doi:10.1016/j.tibtech.2010.07.006

Chen X, Schluesener HJ (2008) Nanosilver: a nanoproduct in medical application. Toxicol Lett 176:1-12. doi:10.1016/j.toxlet.2007.10.004

Chen Z, Kang L, Wang Z et al (2014) Recent progress in the research of biomaterials regulating cell behavior. RSC Adv 4:63807-63816. doi:10.1039/C4RA05534A

Ciancaglini P, Simão AMS, Bolean M et al (2012) Proteoliposomes in nanobiotechnology. Biophys Rev 4:67-81. doi:10.1007/s12551011-0065-4

Costa N, Maquis PM (1998) Biomimetic processing of calcium phosphate coating. Med Eng Phys 20:602-606

Costa DO, Allo BA, Klassen R et al (2012) Control of surface topography in biomimetic calcium phosphate coatings. Langmuir 28:38713880. doi:10.1021/la203224a

Cruz MAE, Ramos AP (2016) Bioactive CaCO3/poly(acrylic acid)/chitosan hybrid coatings deposited on titanium. Surf Coat Technol 294: 145-152. doi:10.1016/j.surfcoat.2016.03.084

Cruz MAE, Ruiz GCM, Faria AN et al (2016) Calcium carbonate hybrid coating promotes the formation of biomimetic hydroxyapatite on titanium surfaces. Appl Surf Sci 370:459-468. doi:10.1016/j. apsusc.2015.12.250

Cüneyt Tas A (2000) Synthesis of biomimetic Ca-hydroxyapatite powders at $37^{\circ} \mathrm{C}$ in synthetic body fluids. Biomaterials 21:1429-1438. doi:10.1016/S0142-9612(00)00019-3

Daghastanli KRP, Ferreira RB, Thedei G et al (2004) Lipid compositiondependent incorporation of multiple membrane proteins into liposomes. Colloids Surf B Biointerfaces 36:127-137. doi:10.1016/j. colsurfb.2004.03.015

De Lima SH, Lopes ML, Maggio B, Ciancaglini P (2005) Na, K-ATPase reconstituted in liposomes: Effects of lipid composition on hydrolytic activity and enzyme orientation. Colloids Surf B Biointerfaces 41:239-248. doi:10.1016/j.colsurfb.2004.12.013 de Souza ID, Cruz MAE, de Faria AN et al (2014a) Formation of carbonated hydroxyapatite films on metallic surfaces using dihexadecyl phosphate-LB film as template. Colloids Surf B Biointerfaces 118C: 31-40. doi:10.1016/j.colsurfb.2014.03.029

de Souza ID, Cruz MAE, de Faria AN et al (2014b) Formation of carbonated hydroxyapatite films on metallic surfaces using dihexadecyl phosphate-LB film as template. Colloids Surf B Biointerfaces 118: 31-40. doi:10.1016/j.colsurfb.2014.03.029

Decher G, Hong JD, Schmitt J (1992) Buildup of ultrathin multilayer films by a self-assembly process : III.Consecutively alternating adsorption of anionic and cationic polyelectrolytes on charged surfaces. Thin Solid Films 210-211:831-835

Decher G, Eckle M, Schmitt J, Struth B (1998) Layer-by-layer assembled multicomposite films. Curr Opin Colloid Interface Sci 3:32-39. doi:10.1016/S1359-0294(98)80039-3

Deng Z, Mortimer G, Schiller T (2009) Differential plasma protein binding to metal oxide nanoparticles. Nanotechnology 20:455101. doi:10.1088/0957-4484/20/45/455101

Dhawan A, Sharma V, Parmar D (2009) Nanomaterials: a challenge for toxicologists. Nanotoxicology 3:1-9. doi:10.1080/17435390802578595

Dong Y, Yang J, Zhang J, Zhang X (2016) Nano-delivery vehicles/ adjuvants for DNA vaccination against HIV. J Nanosci Nanotechnol 16:2126-2133. doi:10.1166/jnn.2016.10947

Ehrlich H (2010) Chitin and collagen as universal and alternative templates in biomineralization. Int Geol Rev 52:661-699. doi:10.1080/00206811003679521

Elkhodiry MA, Momah CC, Suwaidi SR et al (2016) Synergistic nanomedicine: passive, active, and ultrasound-triggered drug delivery in cancer treatment. J Nanosci Nanotechnol 16:1-18. doi:10.1166/jnn.2016.11124

Elsaesser A, Howard CV (2012) Toxicology of nanoparticles. Adv Drug Deliv Rev 64:129-137. doi:10.1016/j.addr.2011.09.001

Fadeel B, Garcia-Bennett AE (2010) Better safe than sorry: understanding the toxicological properties of inorganic nanoparticles manufactured for biomedical applications. Adv Drug Deliv Rev 62:362-374. doi:10.1016/j.addr.2009.11.008

Faraji AH, Wipf P (2009) Nanoparticles in cellular drug delivery. Bioorg Med Chem 17:2950-2962. doi:10.1016/j.bmc.2009.02.043

Faria PEP, Felipucci DNB, Simioni AR et al (2015) Effects of photodynamic process (PDP) in implant osseointegration: a histologic and histometric study in dogs. Clin Implant Dent Relat Res 17:879-890. doi:10.1111/cid.12204

Faucheux N, Schweiss R, Lützow K et al (2004) Self-assembled monolayers with different terminating groups as model substrates for cell adhesion studies. Biomaterials 25:2721-2730. doi:10.1016/j. biomaterials.2003.09.069

Fei Yin Z, Wu L, Gui Yang H, Hua Su Y (2013) Recent progress in biomedical applications of titanium dioxide. Phys Chem Chem Phys 15:4844. doi:10.1039/c3cp43938k

Feng B, Weng J, Yang BC et al (2003) Characterization of surface oxide films on titanium and adhesion of osteoblast. Biomaterials 24:46634670. doi:10.1016/S0142-9612(03)00366-1

Ferris DM, Moodie GD, Dimond PM et al (1999) RGD-coated titanium implants stimulate increased bone formation in vivo. Biomaterials 20:2323-2331

Fricain JC, Bareille R, Ulysse F et al (1998) Evaluation of proliferation and protein expression of human bone marrow cells cultured on coral crystallized in the aragonite of calcite form. J Biomed Mater Res 42:96-102. doi:10.1002/(SICI)1097-4636(199810)42:1<96 ::AID-JBM12>3.0.CO;2-M

Fujihara K, Kotaki M, Ramakrishna S (2005) Guided bone regeneration membrane made of polycaprolactone/calcium carbonate composite nano-fibers. Biomaterials 26:4139-4147. doi:10.1016/j. biomaterials.2004.09.014 
Gao W, Thamphiwatana S, Angsantikul P, Zhang L (2014) Nanoparticle approaches against bacterial infections. Wiley Interdiscip Rev Nanomedicine Nanobiotechnol 6:532-547. doi:10.1002/wnan.1282

Ghalandarlaki N, Alizadeh AM, Ashkani-Esfahani S (2014) Nanotechnology-applied curcumin for different diseases therapy. Biomed Res Int 2014:394264. doi:10.1155/2014/394264

Guidelli EJ, Ramos AP, Zaniquelli MED, Baffa O (2011) Green synthesis of colloidal silver nanoparticles using natural rubber latex extracted from hevea brasiliensis. Spectrochim Acta A Mol Biomol Spectrosc 82:140-145. doi:10.1016/j.saa.2011.07.024

Guidelli EJ, Ramos AP, Zaniquelli MED et al (2012) Synthesis and characterization of silver/alanine nanocomposites for radiation detection in medical applications: the influence of particle size on the detection properties. Nanoscale 4:2884-2893. doi:10.1039/c2nr30090g

Guidelli ÉJ, Kinoshita A, Ramos AP, Baffa O (2013) Silver nanoparticles delivery system based on natural rubber latex membranes. J Nanoparticle Res 15:1536. doi:10.1007/s11051-013-1536-2

Guidelli EJ, Ramos AP, Baffa O (2016) Silver nanoparticle films for metal enhanced luminescence: toward development of plasmonic radiation detectors for medical applications. Sensors Actuators B Chem 224:248-255. doi:10.1016/j.snb.2015.10.024

Gupta AK, Gupta M (2005) Synthesis and surface engineering of iron oxide nanoparticles for biomedical applications. Biomaterials 26: 3995-4021. doi:10.1016/j.biomaterials.2004.10.012

Gupta AK, Naregalkar RR, Vaidya VD, Gupta M (2007) Recent advances on surface engineering of magnetic iron oxide nanoparticles and their biomedical applications. Nanomedicine 2:23-39. doi:10.2217/17435889.2.1.23

Han YJ, Aizenberg J (2003) Face-selective nucleation of calcite on self-assembled monolayers of alkanethiols: effect of the parity of the alkyl chain. Angew Chem Int Ed 42:3668-3670. doi:10.1002/anie.200351655

Hanawa T (2011) A comprehensive review of techniques for biofunctionalization of titanium. J Periodontal Implant Sci 41:263272. doi:10.5051/jpis.2011.41.6.263

Hartono D, Qin WJ, Yang KL, Yung LYL (2009) Imaging the disruption of phospholipid monolayer by protein-coated nanoparticles using ordering transitions of liquid crystals. Biomaterials 30:843-849. doi:10.1016/j.biomaterials.2008.10.037

He J, Zhou W, Zhou X et al (2008) The anatase phase of nanotopography titania plays an important role on osteoblast cell morphology and proliferation. J Mater Sci Mater Med 19:34653472. doi:10.1007/s10856-008-3505-3

Hendesi H, Barbe MF, Safadi FF et al (2015) Integrin mediated adhesion of osteoblasts to connective tissue growth factor (CTGF/CCN2) induces cytoskeleton reorganization and cell differentiation. PLoS One 10:1-20. doi:10.1371/journal.pone.0115325

Hong H, Shi J, Yang Y et al (2011) Cancer-targeted optical imaging with fluorescent zinc oxide nanowires. Nano Lett 11:3744-3750. doi: $10.1021 / \mathrm{nl} 201782 \mathrm{~m}$

Hotchkiss KM, Reddy GB, Hyzy SL et al (2016) Titanium surface characteristics, including topography and wettability, alter macrophage activation. Acta Biomater 31:425-434. doi:10.1016/j. actbio.2015.12.003

Ierardi DF, Pizauro JM, Ciancaglini P (2002) Erythrocyte ghost cell-alkaline phosphatase: construction and characterization of a vesicular system for use in biomineralization studies. Biochim Biophys Acta Biomembr 1567:183-192. doi:10.1016/S0005-2736(02)00615-6

Jalota S, Bhaduri S, Tas A (2007) Osteoblast proliferation on neat and apatite-like calcium phosphate-coated titanium foam scaffolds. Mater Sci Eng C 27:432-440. doi:10.1016/j.msec.2006.05.052

Jayaraman M, Meyer U, Bühner M et al (2004) Influence of titanium surfaces on attachment of osteoblast-like cells in vitro. Biomaterials 25:625-631. doi:10.1016/S0142-9612(03)00571-4
Jiang J, Oberdörster G, Elder A et al (2008) Does nanoparticle activity depend upon size and crystal phase? Nanotoxicology 2:33-42. doi: $10.1080 / 17435390701882478$

Jin HE, Jang J, Chung J et al (2015) Biomimetic self-templated hierarchical structures of collagen-like peptide amphiphiles. Nano Lett 15: 7138-7145. doi:10.1021/acs.nanolett.5b03313

Karmali PP, Simberg D (2011) Interactions of nanoparticles with plasma proteins: implication on clearance and toxicity of drug delivery systems. Expert Opin Drug Deliv 8:343-357. doi:10.1517/17425247.2011.554818

Kasemo B (2002) Biological surface science. Surf Sci 500:656-677. doi:10.1016/S0039-6028(01)01809-X

Khang D, Choi J, Im Y-M et al (2012) Role of subnano-, nano- and submicron-surface features on osteoblast differentiation of bone marrow mesenchymal stem cells. Biomaterials 33:5997-6007. doi:10.1016/j.biomaterials.2012.05.005

Kilpadi KL, Chang PL, Bellis SL (2001) Hydroxylapatite binds more serum proteins, purified integrins, and osteoblast precursor cells than titanium or steel. J Biomed Mater Res 57:258-267. doi:10.1002/1097-4636 (200111)57:2<258::AID-JBM1166>3.0.CO;2-R

Kim JS, Yoon T-J, Yu KN et al (2005) Toxicity and tissue distribution of magnetic nanoparticles in mice. Toxicol Sci 89:338-347. doi:10.1093/toxsci/kfj027

Klymov A, Prodanov L, Lamers E et al (2013) Understanding the role of nano-topography on the surface of a bone-implant. Biomater Sci 1: 135-151. doi:10.1039/C2BM00032F

Koch FP, Weng D, Krämer S et al (2010) Osseointegration of one-piece zirconia implants compared with a titanium implant of identical design: a histomorphometric study in the dog. Clin Oral Implants Res 21:350-356. doi:10.1111/j.1600-0501.2009.01832.x

Kokubo T, Takadama H (2006) How useful is SBF in predicting in vivo bone bioactivity? Biomaterials 27:2907-2915. doi:10.1016/j. biomaterials.2006.01.017

Kokubo T, Kushitani H, Sakka S et al (1990) Solutions able to reproduce in vivo surface-structure changes in bioactive glass-ceramic A-W3. J Biomed Mater Res 24:721-734. doi:10.1002/jbm.820240607

Kroll A, Pillukat MH, Hahn D, Schnekenburger J (2009) Current in vitro methods in nanoparticle risk assessment: limitations and challenges. Eur J Pharm Biopharm 72:370-377. doi:10.1016/j.ejpb.2008.08.009

Krug HF, Wick P (2011) Nanotoxicology: an interdisciplinary challenge. Angew Chem Int Ed 50:1260-1278. doi:10.1002/anie.201001037

Kubota S, Johkura K, Asanuma K et al (2004) Titanium oxide nanotubes for bone regeneration. J Mater Sci Mater Med 15:1031-1035. doi:10.1023/B:JMSM.0000042689.78768.77

Kuna JJ, Voïtchovsky K, Singh C et al (2009) The effect of nanometrescale structure on interfacial energy. Nat Mater 8:837-842. doi:10.1038/nmat2534

Kunzmann A, Andersson B, Thurnherr T et al (2011) Toxicology of engineered nanomaterials: focus on biocompatibility, biodistribution and biodegradation. Biochim Biophys Acta Gen Subj 1810:361373. doi:10.1016/j.bbagen.2010.04.007

Kwok DY, Neumann AW (1999) Contact angle measurement and contact angle interpretation. Adv Colloid Interface Sci 81:167-249. doi:10.1016/S0001-8686(98)00087-6

Lampin M, Warocquier-Clérout LC et al (1997) Correlation between substratum roughness and wettability, cell adhesion, and cell migration. J Biomed Mater Res 36:99-108

Le Guéhennec L, Soueidan A, Layrolle P, Amouriq Y (2007) Surface treatments of titanium dental implants for rapid osseointegration. Dent Mater 23:844-854. doi:10.1016/j.dental.2006.06.025

Liao H, Nehl CL, Hafner JH (2006) Biomedical applications of plasmon resonant metal nanoparticles. Nanomedicine (London) 1:201-208. doi:10.2217/17435889.1.2.201

Lim JY, Taylor AF, Li Z et al (2005) Integrin expression and osteopontin regulation in human fetal osteoblastic cells mediated by substratum surface characteristics. Tissue Eng 11:19-29. doi:10.1089/ten.2005.11.19 
Liu D, Yang F, Xiong F, Gu N (2016a) The smart drug delivery system and its clinical potential. Theranostics 6:1306-1323. doi: $10.7150 /$ thno. 14858

Liu H, Zhang J, Chen X et al (2016b) Application of iron oxide nanoparticles in glioma imaging and therapy: from bench to bedside. Nanoscale 8:7808-7826. doi:10.1039/c6nr00147e

Liu T-Y, Liao H-C, Lin C-C et al (2006) Biofunctional ZnO nanorod arrays grown on flexible substrates. Langmuir 22:5804-5809. doi:10.1021/la052363o

Liu Y, Chen C (2015) Role of nanotechnology in HIV/AIDS vaccine development. Adv Drug Deliv Rev 103:76-89. doi:10.1016/j. addr.2016.02.010

Longo JPF, Leal SC, Simioni AR et al (2012) Photodynamic therapy disinfection of carious tissue mediated by aluminum-chloridephthalocyanine entrapped in cationic liposomes: an in vitro and clinical study. Lasers Med Sci 27:575-584. doi:10.1007/s10103011-0962-6

Lopez E, Vidal B, Berland S et al (1992) Demonstration of the capacity of nacre to induce bone formation by human osteoblasts maintained in vitro. Tissue Cell 24:667-679. doi:10.1016/0040-8166(92)90037-8

Lundqvist M, Stigler J, Cedervall T et al (2011) The evolution of the protein corona arouns nanoparticles: a test study. ACS Nano 5: 7503-7509

Lvov Y, Ariga K, Ichinose I, Kunitake T (1995) Assembly of multicomponent protein films by means of electrostatic layer-by-layer adsorption. J Am Chem Soc 117:6117-6123. doi:10.1021/ja00127a026

Lynch I, Dawson KA (2008) The key role of protein-nanoparticle interactions in nanomedicine and. Nano Today 3:40-47

Madni MA, Sarfraz M, Rehman M et al (2014) Liposomal drug delivery: a versatile platform for challenging clinical applications. J Pharm Pharm Sci 17:401-426

Mahmoudi M, Hofmann H, Rothen-Rutishauser B, Petri-Fink A (2012) Assessing the in vitro and in vivo toxicity of superparamagnetic iron oxide nanoparticles. Chem Rev 112:2323-2338. doi:10.1021/cr2002596

Martin JY, Schwartz Z, Hummert TW et al (1995) Effect of titanium surface roughness on proliferation, differentiation, and protein synthesis of human osteoblast-like cells (MG63). J Biomed Mater Res 29:389-401. doi: $10.1002 / j b m .820290314$

McNamara LE, McMurray RJ, Biggs MJP et al (2010) Nanotopographical control of stem cell differentiation. J Tissue Eng 2010:120623. doi:10.4061/2010/120623

Menzies KL, Jones L (2010) The impact of contact angle on the biocompatibility of biomaterials. Optom Vis Sci 87:387-399. doi:10.1097/OPX.0b013e3181da863e

Moyano DF, Rotello VM (2011) Nano meets biology: structure and function at the nanoparticle interface. Langmuir 27:10376-10385. doi:10.1021/la2004535

Nogueira LFB, Maniglia BC, Pereira LS et al (2016) Formation of carrageenan-CaCO3 bioactive membranes. Mater Sci Eng C 58:16. doi:10.1016/j.msec.2015.08.021

Nowack B, Bucheli TD (2007) Occurrence, behavior and effects of nanoparticles in the environment. Environ Pollut 150:5-22. doi:10.1016/j.envpol.2007.06.006

Oberdörster G (2010) Safety assessment for nanotechnology and nanomedicine: concepts of nanotoxicology. J Intern Med 267:89105. doi:10.1111/j.1365-2796.2009.02187.x

Oh J, Feldman MD, Kim J et al (2006) Detection of magnetic nanoparticles in tissue using magneto-motive ultrasound. Nanotechnology 17:4183-4190. doi:10.1088/0957-4484/17/16/031

Olszta MJ, Cheng X, Jee SS et al (2007) Bone structure and formation: a new perspective. Mater Sci Eng R Rep 58:77-116. doi:10.1016/j. mser.2007.05.001

Özkurt Z, Kazazoğlu E (2011) Zirconia dental implants: a literature review. J Oral Implantol 37:367-376. doi:10.1563/AAID-JOI-D-0900079
Pantarotto D, Briand J-P, Prato M, Bianco A (2004a) Translocation of bioactive peptides across cell membranes by carbon nanotubes. Chem Commun (Camb) 1:16-17. doi:10.1039/b311254c

Pantarotto D, Singh R, McCarthy D et al (2004b) Functionalized carbon nanotubes for plasmid DNA gene delivery. Angew Chem Int Ed 43: 5242-5246. doi:10.1002/anie.200460437

Pastorin G, Wu W, Wieckowski S et al (2006) Double functionalization of carbon nanotubes for multimodal drug delivery. Chem Commun (Camb) 1:1182-1184. doi:10.1039/b516309a

Pastorino L, Dellacasa E, Scaglione S et al (2014) Oriented collagen nanocoatings for tissue engineering. Colloids Surf B: Biointerfaces 114:372-378. doi:10.1016/j.colsurfb.2013.10.026

Piattelli A, Podda G, Scarano A (1997) Clinical and histological results in alveolar ridge enlargement using coralline calcium carbonate. Biomaterials 18:623-627. doi:10.1016/S0142-9612(96)00158-5

Prato M, Kostarelos K, Bianco A (2008) Functionalized carbon nanotubes in drug design and discovery. Acc Chem Res 41:60-68

Puleo DA, Nanci A (1999) Understanding and controlling the bone-implant interface. Biomaterials 20:2311-2321

Quéré D (2008) Wetting and roughness. Annu Rev Mater Res 38:71-99. doi:10.1146/annurev.matsci.38.060407.132434

Rack HJ, Qazi JI (2006) Titanium alloys for biomedical applications. Mater Sci Eng C 26:1269-1277. doi:10.1016/j.msec.2005.08.032

Rammelt S, Illert T, Bierbaum S et al (2006) Coating of titanium implants with collagen, RGD peptide and chondroitin sulfate. Biomaterials 27:5561-5571. doi:10.1016/j.biomaterials.2006.06.034

Ramos AP, Nobre TM, Montoro LA, Zaniquelli MED (2008) Calcium carbonate particle growth depending on coupling among adjacent layers in hybrid LB/LbL films. J Phys Chem B 112:14648-54. doi:10.1021/jp8023793

Ramos AP, Espimpolo DM, Zaniquelli MED (2012) Influence of the type of phospholipid head and of the conformation of the polyelectrolyte on the growth of calcium carbonate thin films on $\mathrm{LB} / \mathrm{LbL}$ matrices. Colloids Surf B: Biointerfaces 95:178-185. doi:10.1016/j. colsurfb.2012.02.040

Ravi-Kumar MN (2000) Nano and microparticles as controlled drug delivery devices. J Pharm Pharm Sci 3:234-258

Reimhult E (2015) Nanoparticle-triggered release from lipid membrane vesicles. New Biotechnol 32:665-672. doi:10.1016/j.nbt.2014.12.002

Riehle MO, Dalby MJ, Johnstone H et al (2003) Cell behaviour of rat calvaria bone cells on surfaces with random nanometric features. Mater Sci Eng C 23:337-340. doi:10.1016/S0928-4931(02)00282-5

Rigos CF, Nobre TM, Zaniquelli MED et al (2008) The association of Na, K-ATPase subunits studied by circular dichroism, surface tension and dilatational elasticity. J Colloid Interface Sci 325:478-484. doi:10.1016/j.jcis.2008.06.011

Rosales-Leal JI, Rodríguez-Valverde MA, Mazzaglia G et al (2010) Effect of roughness, wettability and morphology of engineered titanium surfaces on osteoblast-like cell adhesion. Colloids Surf A Physicochem Eng Asp 365:222-229. doi:10.1016/j.colsurfa.2009.12.017

Saji VS, Choe HC, Young KWK (2010) Nanotechnology in biomedical applications - a review. Int J Nano Biomater 3:119-139

Santos LER, Colhone MC, Daghastanli KRP et al (2009) Lipid microspheres loaded with antigenic membrane proteins of the leishmania amazonensis as a potential biotechnology application. J Colloid Interface Sci 340:112-118. doi:10.1016/j.jcis.2009.08.025

Sato M, Slamovich EB, Webster TJ (2005) Enhanced osteoblast adhesion on hydrothermally treated hydroxyapatite/titania/poly(lactide-coglycolide) sol-gel titanium coatings. Biomaterials 26:1349-1357. doi:10.1016/j.biomaterials.2004.04.044

Schmidt RC, Healy KE (2009) Controlling biological interfaces on the nanometer length scale. Biomed Mater Res A 90:1252-1261. doi:10.1002/jbm.a.32501

Sharma P, Mehra NK, Jain K, Jain N (2016) Biomedical applications of carbon nanotubes: a critical review. Curr Drug Deliv 13:796-817 
Shehata T, Ogawara K, Higaki K, Kimura T (2008) Prolongation of residence time of liposome by surface-modification with mixture of hydrophilic polymers. Int J Pharm 359:272-279. doi:10.1016/j. ijpharm.2008.04.004

Simão AMS, Yadav MC, Ciancaglini P, Millán JL (2010a) Proteoliposomes as matrix vesicles' biomimetics to study the initiation of skeletal mineralization. Braz J Med Biol Res 43:234-241. doi:10.1590/S0100-879X2010007500008

Simão AMS, Yadav MC, Narisawa S et al (2010b) Proteoliposomes harboring alkaline phosphatase and nucleotide pyrophosphatase as matrix vesicle biomimetics. J Biol Chem 285:7598-7609. doi:10.1074/jbc.M109.079830

Simão AMS, Bolean M, Cury TAC et al (2015) Liposomal systems as carriers for bioactive compounds. Biophys Rev 7:391-397. doi:10.1007/s12551-015-0180-8

Surmenev RA (2011) A review of plasma-assisted methods for calcium phosphate-based coatings fabrication. Surf Coat Technol 206:20352056. doi:10.1016/j.surfcoat.2011.11.002

Surmenev RA, Surmeneva MA, Ivanova AA (2014) Significance of calcium phosphate coatings for the enhancement of new bone osteogenesis: a review. Acta Biomater 10:557-579. doi:10.1016/j. actbio.2013.10.036

Tan AW, Pingguan-Murphy B, Ahmad R, Akbar SA (2012) Review of titania nanotubes: fabrication and cellular response. Ceram Int 38: 4421-4435. doi:10.1016/j.ceramint.2012.03.002

Tanahashi M, Matsuda T (1997) Surface functional group dependence on apatite formation on self-assembled monolayers in a simulated body fluid. J Biomed Mater Res 34:305-315. doi:10.1002/(SICI)10974636(19970305)34:3<305::AID-JBM5>3.0.CO;2-O

Tas AC (2014) The use of physiological solutions or media in calcium phosphate synthesis and processing. Acta Biomater 10:1771-1792. doi:10.1016/j.actbio.2013.12.047

Tian J, Wong KKY, Ho CM et al (2007) Topical delivery of silver nanoparticles promotes wound healing. ChemMedChem 2:129-136. doi:10.1002/cmdc.200600171

Tirrell M, Kokkoli E, Biesalski M (2002) The role of surface science in bioengineered materials. Surf Sci 500:61-83. doi:10.1016/S00396028(01)01548-5

Tovani CB, Zancanela DC, Faria AN et al (2016) Bio-inspired synthesis of hybrid tube-like structures based on $\mathrm{CaCO}_{3}$ and type I-collagen. RSC Adv 6:90509-90515. doi:10.1039/C6RA18984A

Verma A, Stellacci F (2010) Effect of surface properties on nanoparticlecell interactions. Small 6:12-21. doi:10.1002/smll.200901158

Vogler EA (1998) Structure and reactivity of water at biomaterial surfaces. Adv Colloid Interface Sci 74:69-117. doi:10.1016/S00018686(97)00040-7

Walsh D, Furuzono T, Tanaka J (2001) Preparation of porous composite implant materials by in situ polymerization of porous apatite containing $\varepsilon$-caprolactone or methyl methacrylate. Biomaterials 22: 1205-1212. doi:10.1016/S0142-9612(00)00268-4

Wang HF, Huff TB, Zweifel DA et al (2005) In vitro and in vivo twophoton luminescence imaging of single gold nanorods. Proc Natl Acad Sci USA 102:15752-15756. doi:10.1073/pnas.0504892102

Webster TJ, Ejiofor JU (2004) Increased osteoblast adhesion on nanophase metals: Ti, Ti6Al4V, and CoCrMo. Biomaterials 25:47314939. doi:10.1016/j.biomaterials.2003.12.002

Webster TJ, Ergun C, Doremus RH et al (2000) Specific proteins mediate enhanced osteoblast adhesion on nanophase ceramics. J Biomed Mater Res 51:475-483

Wei G, Ma PX (2004) Structure and properties of nano-hydroxyapatite/ polymer composite scaffolds for bone tissue engineering. Biomaterials 25:4749-4757. doi:10.1016/j.biomaterials.2003.12.005
Wennerberg A, Albrektsson T (2009) Effects of titanium surface topography on bone integration: a systematic review. Clin Oral Implants Res 20[Suppl 4]:172-184. doi:10.1111/j.1600-0501.2009.01775.x

Wennerberg A, Hallgren C, Johansson C, Danelli S (1998) A histomorphometric evaluation of screw-shaped implants each prepared with two surface roughnesses. Clin Oral Implants Res 9:1119. doi:10.1034/j.1600-0501.1998.090102.x

Williams KA, Veenhuizen PTM, de la Torre BG, Ramon Eritja CD (2002) Carbon nanotubes with DNA recognition. Nature 420:761

Xia Z, Yu X, Wei M (2012) Biomimetic collagen/apatite coating formation on Ti6Al4V substrates. J Biomed Mater Res B Appl Biomater 100:871-881. doi:10.1002/jbm.b.31970

Xiao F-X, Pagliaro M, Xu Y-J, Liu B (2016) Layer-by-layer assembly of versatile nanoarchitectures with diverse dimensionality: a new perspective for rational construction of multilayer assemblies. Chem Soc Rev 45:3088-3121. doi:10.1039/C5CS00781J

Xu Z, Liang G, Jin L et al (2014) Synthesis of sodium caseinate-calcium carbonate microspheres and their mineralization to bone-like apatite. J Cryst Growth 395:116-122. doi:10.1016/j.jcrysgro.2014.03.023

Yang W, Thordarson P, Gooding JJ et al (2007) Carbon nanotubes for biological and biomedical applications. Nanotechnology 18:1. doi:10.1088/0957-4484/18/41/412001

Yang Y, Kim K, Ong J (2005) A review on calcium phosphate coatings produced using a sputtering process? An alternative to plasma spraying. Biomaterials 26:327-337. doi:10.1016/j.biomaterials.2004.02.029

Yim EKF, Darling EM, Kulangara K et al (2010) Nanotopographyinduced changes in focal adhesions, cytoskeletal organization, and mechanical properties of human mesenchymal stem cells. Biomaterials 31:1299-1306. doi:10.1016/j.biomaterials.2009.10.037

Yoneda JS, Rigos CF, Ciancaglini P (2013) Addition of subunit 1, K+ ions, and lipid restores the thermal stability of solubilized $\mathrm{Na}, \mathrm{K}-$ ATPase. Arch Biochem Biophys 530:93-100. doi:10.1016/j. abb.2009.01.015

Yoneda JS, Rigos CF, De Lourenço TFA et al (2014) Na, K-ATPase reconstituted in ternary liposome: The presence of cholesterol affects protein activity and thermal stability. Arch Biochem Biophys 564:136-141. doi:10.1016/j.abb.2014.09.015

Yoon I-K, Hwang J-Y, Jang W-C et al (2014) Natural bone-like biomimetic surface modification of titanium. Appl Surf Sci 301:401-409. doi:10.1016/j.apsusc.2014.02.090

Yukna RA, Yukna CN (1998) A 5-year follow-up of 16 patients treated with coralline calcium carbonate (Biocoraltm) bone replacement grafts in infrabony defects. J Clin Periodontol 25:1036-1040. doi:10.1111/j.1600-051X.1998.tb02410.x

Zancanela DC, de Faria AN, Simão AMS et al (2016) Multi and single walled carbon nanotubes: effects on cell responses and biomineralization of osteoblasts culture. J Mater Sci Mater Med 27:1-10

Zanello LP, Zhao B, Hu H, Haddon RC (2006) Bone cell proliferation on carbon nanotubes. Nano Lett 6:562-7. doi:10.1021/n1051861e

Zhang Y, Jin R, Zhang L, Liu M (2004) Growth of CaCO3 in the templated Langmuir?Blodgett film of a bolaamphiphilic diacid. New J Chem 28:614. doi:10.1039/b314136e

Zhao HY, Xu XX, Zhang JX et al (2010) Carbon nanotubehydroxyapatite-hemoglobin nanocomposites with high bioelectrocatalytic activity. Bioelectrochemistry 78:124-129. doi:10.1016/j.bioelechem.2009.08.009

Zucolotto V, Daghastanli KRP, Hayasaka CO et al (2007) Using capacitance measurements as the detection method in antigen containing layer by layer films for biosensing. Anal Chem 79:2163-2167. doi:10.1021/ac0616153 